\title{
Historical centers: sustainable economic spaces, management for sustainable projects
}

\author{
R. Jordán ${ }^{1}$, J. Plaut ${ }^{1}$, G. Carlo Magnoli ${ }^{2,3}$, R. M. Pulselli ${ }^{3,4}$ \\ \& E. Tiezzi ${ }^{4}$ \\ ${ }^{I}$ Sustainable Development and Human Settlements Division, \\ United Nations ECLAC, Chile \\ ${ }^{2}$ European Union P.R.I.S.M.A. Project on Sustainable Built Environment, Italy \\ ${ }^{3}$ M.I.T, Cambridge, USA \\ ${ }^{4}$ Department of Chemical and Biosystems Sciences, University of Siena, Italy
}

\begin{abstract}
Historical centers have the potential to unite: different cultures, architectonic and intangible patrimony, goods and services formally and informally produced, financial capitals, different levels of salaries and rents, real estate investment and patrimonial renovation projects, amongst others. This paper studies, in the context of equity and sustainability objectives of city management, the degree of economic "factor" insertion in diverse areas and activities in historical centers. Methodologically, it presents the main factors and issues that constitute challenges for sustainable urban management and proposes a necessary strategy for public policy coordination and investment in city centers.

The main objective is to delineate a sustainable city urban management in terms of its elements, parameters and instruments. This strategy responds to public sector demands regarding management options that could balance the growth and equity in the historical centers of cities.

Some questions that arise in this context are: is there a relation between the economic dimension of historical centers and the social equity and inclusiveness in urban society in the framework of sustainability? Is the search for equity in Latin America and the Caribbean cities the economic management approach in historical centers? In management terms, how do institutions deal with the concepts of center and centrality?

The discussion and analysis of the economic dimension of historical centers in Latin America and the Caribbean and their corresponding potential for urban development and equity will be synthesized based on tendencies, and will build a framework for sustainable urban projects for historical centers in this region.

Keywords: historical center, strategic and sustainable urban management, regional sustainable urban agenda, Latin America and the Caribbean.
\end{abstract}




\section{Economic functions in historical centers}

As stated in recent ECLAC documents prepared for the Thirteenth Meeting of Ministers and High-level Authorities of the Housing and Urban Development Sector in Latin America and the Caribbean, the region is the most urbanized region in the developing world, with an urbanization level rivaling that of many industrialized countries. The region's urbanization level rose from 71\% in 1990 to $75 \%$ in 2000 , at which time its urban population amounted to 380 million, in contrast to 127 million rural inhabitants (ECLAC, 2001a). Moreover, a large proportion of the urban population in the region lives in large cities. The most common type of population movement in the region is migration between cities. Rural to- urban migration, which has declined in absolute terms, is taking on new forms, particularly involving more educated young adults of working age and in situations of widespread civil conflict. The region is also starting to become a source of outward migration to other countries, primarily the United States, and to a much lesser degree Canada, Europe and Oceania.

According to ECLAC estimates, by the beginning of the 2000s the region's urban poor amounted to over 138 million people, of whom 46 million were indigent. While poverty is proportionally lower in cities than in rural areas, the region's high level of urbanization has concentrated most of the population in urban centers, with the result that two out of every three poor people in the region are city dwellers. Urban poverty takes the form of low earnings related to precarious employment, a shortage of educational capital and patrimonial assets, and shows gender-related inequalities. Households headed by women, apart from being over represented among poor households, tend to be more economically and socially vulnerable because of the lower number of workers per household, which makes them more likely to fall below the poverty line in times of crisis.

While economic growth and increased social spending in all the countries have enabled them to make progress in reducing the percentage of people living in poverty, national inequality indices have remained high or deteriorated outright. ECLAC analyses show that wealth factors affect inequity as well as poverty. Average growth in most countries of the region, has been insufficient to overcome problems of poverty. Low growth rates have had negative effects on employment and the creation of new jobs. The sharp decline in the labor absorption capacity of manufacturing and the public sector, in a context of rapid technology absorption and fiscal adjustment, has had at least three effects: (i) the reduction in the number of low-skilled jobs, with a consequent rise in unemployment and informal employment; (ii) a widening of the wage gap between skilled and unskilled workers; and (iii) a downturn in the proportion of secure, stable jobs, particularly low-skill jobs, and greater disparity between skilled and unskilled workers in terms of rights at work [1].

Although urbanization processes have slowed during the past decade, serious challenges continue to exist in the region's urban settlements: a scarcity of public services, marked social inequalities in living conditions, social and spatial segregation, inequality, poverty, unemployment and increased economic vulnerability, environmental degradation, complexities in governance structures 
for urban environmental service provision, pollution, and vulnerability to technological and natural disasters.

The convergence in the urban sphere of economic efficiency constraints (financing issues), social equity concerns (habitability, investment in capitals, employment), the need to internalize environmental costs (management, governance) and to improve urban functionality with respect to regional integration and globalization tensions, present great challenges to urban policy makers on regional, national, sub-national and local levels. In meeting urban challenges, the most effective institutions and policy initiatives will exploit the opportunities globalization and localization present; globalization can provide the impetus for economic growth, while successful localization can empower communities to act as agents of change and give rise to mechanisms to promote transparency and accountability in public sector decision-making.

The discussion and analysis of the economic dimension of Latin American and Caribbean historical centers and their corresponding potential, implies framing the current dynamics of these city areas in relation to globalization tendencies.

It is necessary to recognize that traditional economic functions of production, distribution and consumption of goods and services, from the most sophisticated to the simplest, have a very important place in Latin American and the Caribbean cities. The urbanization level increases to $75 \%$. The level and type of economic insertion of groups and individuals in the "economy of the city" and especially in the historical centers determines the level of access to urban goods and servicestangible and intangible - that are produced in the context of global interchangeable economy [2].

These social and economic asymmetries (various types of insertions) are reflected by important city centers contrasts: social groups that live in them; cultural, architectonic and intangible patrimony; goods and services that are produced, distributed and commercialized formally and informally; wages and rents that are perceived; real estate investment and patrimonial recovery; access to infrastructure and basic services among others.

In city centers, groups and individuals reflect their demands. From the supply side it is organized (spatially and economically) to satisfy different demands and interests. It indicates the strong relationship between the economic dimension of historical centers and access to goods and services (as a measure of equity) considering urban society as a whole. For that reason, economic and social inclusiveness is in our understanding the approach to economic management dimension of historical centers [3].

As a second aspect to be considered, we need to focus our attention in the center- centrality relation in historical centers. In other words, what are the historical center-centrality functions?

Could these centrality functions be "allocated" through a strategic urban management sustainability approach applied to city historical centers?

The center-centrality relationship reveals the tendencies towards institutional, commercial and political appropriation of "values" that hold the historical center and that allows us to differentiate these tendencies from other urban areas. In 
these central areas, the historical center, is "... the place of the difference... the place of sense, the main urban factor of citizen integration." [4]. This shows the constant valuation and appropriation of individuals, groups and institutions of its qualities, especially those of a commercial nature and those of an institutional and political type.

The main objective that is pursued in this appropriation is the best return or gain. In city centers, the best place is sought for sales, distribution and purchase of goods and services; locating a regional or main branch of a transnational company; where institutions of national government are located; obtaining a desirable level of impact in the institutions by citizenship through social manifestations indistinct the specific reclamations.

In other words, firms and companies search to appropriate this urban area that allows them better access to levels of tangible and intangible returns and gains; either from an economic-commercial perspective or as from a politicalinstitutional objective. The historical urban centers offer these conditions.

These concepts refer to the dynamics of historical centers; these conditions reveal the importance of urban intervention in historical centers themselves, through a strategic management of the historical city centers; in this sense, seeking to put in place a particular management for these areas in the debate and practice on urban public policies.

Nevertheless, it would not be possible without an analysis and evaluation of the functionality of historical centers. In other words, which would be the best management approach? A search through strategic measures, the recreation of traditional conditions so that these central areas gain once again a "classic functionality", and/or rather create the conditions necessary to give the area a "new functionality", that is, appearing in the context of globalization dynamics.

The debate in this sense indicates the idea of not introducing a management that "freezes" the conditions and characteristics that historical centers have (from an architectural and patrimony perspective), but rather introduces (in the proposals) transformations, changes, expanding and accumulating tangible and social capital. It can be done through preserving the identity through historical patrimony preservation. In this sense, the latter is more an instrument than an objective.

More specifically what is accumulated in an historical center and who accumulates it?

The economic dimension of historical centers, with its traditional economic functions and appropriation tendencies, by commercial and political institutions, tie together other factors referring necessarily to the matter of accumulation of a varied range of "capitals" in historical centers.

At least three types of capitals can be distinguished: social, physical and political-institutional. In this sense, is essential the analysis of economic appropriation, in terms of who wants and needs to have access to the "center" to achieve appropriation of a part of these capitals, looking for a best possible return and gains.

A specific analysis (based on Latin America and European experience) leads us to the conviction of the appearance of a "new functionality". It arises from a 
profound transformation of economic and social functions in historical centers. The objectives and interest of individuals, firms, and social groups has not changed much but the type of goods and services and capitals to be provided is mostly different.

At a micro-center level (part of a historical center), "new functions" arise to a large extent, as multiple effects of the financial economic globalization that has been experienced for decades. One of these multiple effects that have immediate expression in the center refers to a new order in terms of economic agents in the manifold and varied activities that are localized in these areas; and to a "new logic" in economic dynamics that result. For this, it is necessary to recognize the distinctions between urban centers and historical centers, as two types of centralities in Latin American cases (Carrión, 2003:134). In these, the consolidation of economic activities of sub contract services that support and are functional to other economic activities related to transnational companies of great spread or great impact in the context of globalization productive and financial dynamics have been noticed. These "new arrangements" have also been identified and researched in urban centers of developed countries in depth (Sassen, 2003). It would be possible to state that nowadays the historical centers functionally contribute to the national urban economy - and to the transnational economy - through "global chaining"; an activity that previously did not exist or it was not so evident. At the same time, spatially this strengthens other functional dimensions of historical centers, creating a process of strong "microeconomic urban clusters" [5].

From a social point of view, globalization has introduced a new dimension of urban poverty to city centers; economic informality finds its place in commercial activities in urban centers. The informal sector uses public spaces guided by high accessibility in these areas. It is perceiving the necessity - and in a way the opportunity - that exists "to act on time" through public-private management. Guided by governments, with the participation of poor social groups, management of urban city center upgrades will have to solve the problems in run-down urban areas but with a great potential of performing centrality functions. Systematic and participative management could solve the problems of poverty, precariousness and urban marginality in these areas. For example initiatives of social and economic urban renovation in the Santiago CBD, that can also be seen in Rome, Paris or Berlin, together with "meso urban projects", have achieved a strong position on the Urban Reform agenda that the Chilean Government is carrying out [6].

Another relevant aspect from this new functionality of historical centers is what happens with expansion and spatial growth in these central areas. In effect, central city dynamics are influenced by growth dynamics in peripheral zones. New centers and centralities are created, especially in metropolitan cities as a result of a "frog leap" form of metropolitan spatial growth. "...in Latin America there are cases of new urban centralities that are registered in the logics of globalization and that tend to produce a "wash out" effect of historical centers which in turn are "peripherized..." [7]. Old centers become a "periphery" of new centers. For example, in the Metropolitan Area of Santiago de Chile, the 
city traditional center has lost some attributes and conditions of an urban center but not the historical center - to other areas in the periphery that nowadays are characterized by their significant dynamism.

\section{Strategic management of historical urban centers: a regional agenda for sustainable urban development}

The logic of historical center dynamics and their functionality leads to the need for developing a strategic urban management agenda, not only at a debate level but also at a practical one. In this sense, this discussion first of all needs to emphasize not only the objectives of urban management, but also the strategic action axes that have been set up for Latin America and the Caribbean by the United Nations in collaboration with different sectorial regional and international Forums and Conferences.

There are four main objectives of strategic urban management: to improve urban sustainability in economic, social and environmental aspects; to improve habitability and urban functionality standards; to improve urban governance standards and to overcome urban poverty with economic and social development.

These objectives and the strategic management that result from its operation in cities and territories, conforms to a Regional Agenda for Sustainable Urban Development.

In Latin America and the Caribbean regional context, there are different initiatives for urban reforms that include regulatory aspects as well management proposals (for example in the cases of Chile and Brazil) for a better level of territorial competitiveness. The Regional Agenda for Sustainable Urban Development focuses the attention on five main aspects: public spaces, public services, employment and income, land and housing; which are controlled by three main instrumental aspects: finance, governance - participation and institutionalism - norms. These arise not only from the analysis and evaluation of management conditions in Latin American and Caribbean urban areas, but at the same time, due to the entailment of strengths and potentialities of these areas.

The concern for public spaces appears from the potential to generate social capital that allows improvements not only in citizenship but in the involvement of individuals and groups for sustainable economic and social improvement in these areas.

Policies creating jobs and increasing wages combat this problem by decreasing critical unemployment levels to some extent. Public services are approached not only from the perspective of a defecit in the network but also in the quality of services. Land use policy analyzes innovative alternatives for access, effectively legally entitling the sectors to use fewer resources. At the same time, this activates management mechanisms, which improve efficiency in the use of urban resources. Housing policies seek to promote forms of intervention that improve standards, in terms of quality and quantity using integral methodological and managerial approaches to slum upgrading. Every 
one of the aspects focuses on its most basic contribution in order to overcome poverty and urban precariousness in the region.

Objectives of urban management as well as aspects of urban intervention at a regional level outline a strong entailment with actions that can be generated within historical centers. It considers potentialities of an integral intervention that "mixes" the programmatic and instrumental axes of the agenda, bearing in mind that all are needed in historical center management strategies.

\section{Sustainable strategic management of historical centers}

Historical center crisis can be understood as a true opportunity where a complex mixture of initiatives of individuals and groups that have their own nature, experience and dynamics through time can be capitalized upon. Some historical centers of the Region are experiencing real uncertainty and physical, economic and socio-cultural degradation with former administration and management schemes that do not guarantee their future sustainability and present a nonefficient institutional performance. At the same time, in some Latin American cities that have faced varied and intense problems, it has been possible replace historical center management with innovative mechanisms for the recovery and valuation of these areas. Mexico City is a good example, where private capital has introduced forms of financial management schemes in order to "rescue" the city center. Quito (Ecuador) shows how international credit can build up a "management machinery" under the coordination of the local government with enterprise logic and citizenship participation. In the city of Cordoba (Argentina) a strong process of central city decentralization has been developed in the context of the creation of a public-private developed agency for the city.

Considering the statement that the "...universe highly differentiated of historical centers expresses wealth and it demands analytical creativity..." [7] and taking into account that there is not a "unique model" that can generate "successful results", it is necessary to remember what elements are necessary for developing a strategic urban management in historical centers. Consequently the following proposed factors are set out as "reminders" for policy and strategic management design, which have arisen out of the experience and projects of ECLAC and European Organizations, which are capitalized throughout time.

\subsection{Patrimonial scanner: individuals and groups}

Replacing sustainable strategic management in historical centers first of all requires an initial diagnosis and analysis that identifies and reports two central factors in historical centers, which will be fundamental for policy proposals. The first step is to identify who will be affected by the intervention; who can be involved according to rights and obligations and who will be needed to negotiate in order to articulate and redirect actions, efforts and resources. It is here that the "patrimonial individuals or groups in the development of historical centers" or "patrimonial actors" are defined. It is essential to notice some main parties: public sector, enterprise private sector, citizen institutions and NGO's, amongst 
others. It is important to analyze the different levels of their capacity to innovate and to manage such strategies, and their functions and rights in the historical centers. It is also necessary to recognize their perception of the historical center's development. In other words, it is necessary to be able to easily report the attitudes that these individuals and groups demonstrate and at the same time, and most important, their suitability, due to their insertion and adaptability for acquiring new roles in the processes and projects that are the base of strategic management in urban centers. This is important in order to analyze the degree of sustainability that can be achieved with this strategy considering these groups of participants and for evaluating the possibility of attracting new strategic partners.

The second step is to identify the relationship between these parties and the economic activities that are recognized as specific to historical center and that are located in it. The identification of economic dynamics can be ascertained by "scanning" the parties interested in the historical center, in the sense of their activities, functions and relations. Considering, for example: levels and types of economic activity; supply and demand for recreational, cultural and commercial activities; dynamics of the informal sector and the impacts on the quality of life of inhabitants in city centers; the presence of transnational companies and sub contract economic "chains", amongst others.

An analysis that emphasizes the strengths, weakness, opportunities and threats to city center dynamics and a study of the potential for economic activities are essential for achieving a high level of sustainability.

\subsection{Co-management equation}

A "co-management equation" results from the analysis and evaluation of the economic dimension of historical centers. It is based on the consolidation of "new functions" and dynamics that city centers have experienced. This can lead management institutions to distinguish two types of target objectives. They become the "nucleus" of the processes and projects that include the developments that are part of the management strategy for historical centers. They become the main "actors" in the co-management process. Within enterprise management logic, the relationship between private and public sector identifies two types of management targets: "commercial-institutional targets", and "social targets". The challenge is to identify some "base line activities" as an input for a negotiated strategy to develop economic dynamics in the historical centers. From the public sector point of view, it is important to emphasize needs and demands from individuals and groups with a territorial scope as social targets. They must become a part of the commercial institutional and economic strategy of the city center as a whole. The role of the public sector is to guarantee economic sustainability not only for firms and enterprises that operate in city centers but also for poor individuals and groups who live in the area.

In relation to the social target, these individuals and groups linked to the economic management strategy at the same time present openings and vulnerabilities. The openings must be understood with regard to the programmatic and instrumental axes of the Regional Agenda for Sustainable Urban Development previously noted and specifically related to the economic 
dimension that these centers present in order to promote employment and income increase. It is also realistic to note that the same target displays its correspondent vulnerability in economic, financial, legal, and social terms; especially because of urban poverty and precariousness within city centers. Potentiality and vulnerability, which are parts of the social target, justifies special attention from the government. In this sense, public policy has the possibility of undertaking and harnessing plans, policies, programs and projects that are oriented in an integral approach to the promotion and production of tangible and intangible goods and services in the historical centers.

The analysis implicit in the "co-management equation" allows us, among other aspects, to: work on the basis of a realistic approach that optimizes the potential of functions of individuals and groups in historical center development through an evaluation of its specific functions; incorporate citizenship as a true reasonable input to generate commitment and attitudes; generate a process that is based not only on an altruistic approach but on "economic and social responsibility" in the private sector, with direct and concrete benefits in the quality of life in historical centers.

\section{Final considerations}

Some aspects of the potential of actual economic dynamics in historical centers from the perspective of a strategic sustainable management have been outlined. The "new functionality" that has arisen from changes in dynamics and functions that experience these areas (nodes) in the cities in Latin America and the Caribbean, demands to center the analysis and the corresponding proposals in those precise context conditions (enabling framework) that requires a strong compromise from different government institutions in the framework of a city center strategic sustainable management operations.

One of the most important arguments in these sense, and one of great relevance, is the strong relationship that historical centers development as economic spaces has with equity and inclusiveness in city social and economic development. Equity at different levels: as a basis for new standards for urban habitability and functionality; equity and inclusiveness in relation to social challenges for the environmental and for social and economic sustainability. In other words, through strategic management of historical centers, it will be possible to overcome poverty and precariousness and at the same time, acquire high levels of economic growth.

The strategy proposed "uses" city center development as an instrument for urban development. This management has the potential to introduce an economically productive "gravitational weight" of historical centers for urban development. Efficient management will contribute to the development of sustainable projects based on a strategic management in historical centers.

Finally, and in relation to what has been stated, ECLAC and European organizations' experiences assign a special attention and importance to the aspects concerning proper management instruments (finance, governance - 
participation and institutionalism - norm), before an exhaustive development of recurrent agendas in relation to strategic planning in historical centers.

\section{References}

[1] Kaztman, R., 'La dimensión espacial en las políticas de superación de la pobreza urbana”, Serie Medio Ambiente y Desarrollo N 59, División de Desarrollo Sostenible y Asentamientos Humanos, CEPAL, Santiago, 2003.

[2] Jordán, R. y Simioni, D., “Guía de gestión urbana”, División de Desarrollo Sostenible y Asentamientos Humanos, Comisión Económica para América Latina y el Caribe (CEPAL) y Cooperazione Italiana, Santiago, 2003.

[3] Arízaga G., D., “Recuperación de las áreas centrales”, en Jordán R. y Simioni D. comp. "Gestión urbana para el Desarrollo Sostenible en América Latina y el Caribe", División de Desarrollo Sostenible y Asentamientos Humanos, Comisión Económica para América Latina y el Caribe (CEPAL) y Cooperazione Italiana, Santiago, 2003.

[4] Borja, J., " Ciudad y planificación: La urbanística para las ciudades de América Latina”, en Balbo, M., Jordán, R., Simioni, D., "La ciudad inclusiva”, División de Desarrollo Sostenible y Asentamientos Humanos, Comisión Económica para América Latina y el Caribe (CEPAL) y Cooperazione Italiana, Santiago, 2003.

[5] Sassen, S., "Los Espectros de la Globalización", Fondo de Cultura Económica de Argentina, Buenos Aires, 2003.

[6] Ministerio de Vivienda y Urbanismo - MINVU, "Anillo Interior de Santiago: un desafio de gestión urbana estratégica”, Santiago, 2003.

[7] Carrión, F. "Ciudad y Centros Históricos: Centros Históricos y actores patrimoniales", en Balbo, M., Jordán, R., Simioni, D., "La ciudad inclusiva”, División de Desarrollo Sostenible y Asentamientos Humanos, Comisión Económica para América Latina y el Caribe (CEPAL) y Cooperazione Italiana, Santiago, 2003. 